\title{
Diagnosis and management of Sandifer syndrome in children with intractable neurological symptoms
}

\author{
Irina Mindlina ${ }^{1}$ (D) \\ Received: 3 September 2019 /Revised: 27 December 2019 / Accepted: 29 December 2019 / Published online: 11 January 2020 \\ (C) The Author(s) 2020
}

\begin{abstract}
Sandifer syndrome is a rare complication of gastro-oesophageal reflux disease (GERD) when a patient presents with extraoesophageal symptoms, typically neurological. The aim of this study was to review the existing literature and describe a typical presentation and most appropriate investigations and management for the Sandifer syndrome. A comprehensive literature search was performed via PubMed, Cochrane Library and NHS Evidence databases. Twenty-seven cases and observational studies were identified. The literature demonstrates that presenting symptoms of Sandifer's may include any combination of abnormal movements and/or positioning of head, neck, trunk and upper limbs, seizure-like episodes, ocular symptoms, irritability, developmental and growth delay and iron-deficiency anaemia. A 24-h oesophageal $\mathrm{pH}$ monitoring was positive in all the cases of Sandifer's where it was performed, while upper GI endoscopy \pm biopsy and barium swallow were diagnostic only in a subset of cases. Successful treatment of the underlying gastro-oesophageal pathology led to a complete or near-complete resolution of the neurological symptoms in all of the cases.

Conclusion: It is evident from the literature that many patients with Sandifer syndrome were originally misdiagnosed with various neuropsychiatric diagnoses that led to unnecessary testing and ineffective medications with significant side effects. Earlier diagnosis of Sandifer's would have allowed to avoid them.
\end{abstract}

What is Known:

- Sandifer syndrome is a rare complication of gastro-oesophageal reflux disease (GERD) when a patient presents with extraoesophageal symptoms, typically neurological.

- It may be difficult to recognise due to its non-specific presentation and lack of gastrointestinal symptoms.

What is New:

- Based on the review of 44 clinical cases of suspected Sandifer syndrome, the clinical picture was clarified: the presenting symptoms of Sandifer's may include any combination of abnormal movements and/or positioning of head, neck, trunk and upper limbs, seizure-like episodes, ocular symptoms, irritability, developmental and growth delay and iron-deficiency anaemia.

- Successful treatment of the underlying gastro-oesophageal pathology led to a complete or near-complete resolution of the neurological symptoms in all of the reviewed cases.

Keywords Sandifer syndrome $\cdot$ Gastro-oesophageal reflux disease $\cdot$ Misdiagnosis $\cdot$ Intractable neurological symptoms
Abbreviations
EEG Electroencephalography
GERD Gastro-oesophageal reflux disease
GI Gastro-intestinal
MRI Magnetic resonance imaging

Communicated by Peter de Winter

Irina Mindlina

irina.mindlina@gmail.com

1 School of Clinical Medicine, University of Cambridge, Hills Road, Cambridge CB2 0QQ, UK
NICE National Institute of Clinical Excellence (UK)

NHS National Health Service (UK)

PPI Proton pump inhibitor

\section{Introduction}

Sandifer syndrome is defined as a rare complication of gastrooesophageal reflux disease (GERD) when a patient presents with extraoesophageal symptoms, typically neurological [18]. These symptoms may be as severe as mimicking epileptic seizures or convulsions [23]. Although its pathophysiology is not completely understood, one possible explanation is that 
neurological manifestations are the consequence of vagal reflex with the reflex center in nucleus tractus solitarii [3]. The main difficulty with accurately diagnosing this clinical presentation is that often the overt gastro-intestinal symptoms, such as abdominal pain, vomiting or indigestion, are either absent, or the patient is too young to be able to communicate them. Thus, there is nothing to point the clinician to the direction of GI investigations, and as a result, the vast majority of patients with Sandifer syndrome are originally misdiagnosed with a neurological or a musculoskeletal disorder. This may lead to a range of unnecessary investigations, such as EEG, MRI and electromyographic studies, all of which come back normal. Moreover, this may result in the administration of unnecessary medications, such as anti-epileptic agents, which may have significant negative side effects. The aim of this study is to review the existing literature and describe a typical presentation and most appropriate investigations and management for the Sandifer syndrome, so that it can be considered early on in the differential diagnosis for children with intractable neurological symptoms.

\section{Methodology}

The literature search strategy included conducting a systematic review via Cochrane Library, PubMed and NHS Evidence databases. The search terms and the outcomes are listed below:

- Cochrane library: 'Sandifer* syndrome'

- 1 controlled trial, not relevant

- PubMed search: 'Sandifer* syndrome'

- 86 results in the English language, 27 were relevant

- The following publications were excluded:

Case studies covering only adults

Correspondence that did not include specific patient cases

- NHS Evidence: 'Sandifer* syndrome'

- 8 results, 1 was relevant (NICE guideline)

Overall, 27 case reports and observational studies were available for analysis, covering 44 clinical cases in total.

\section{Results}

The detailed findings of the systematic review are provided in Table 1.
The literature demonstrates that the presenting symptoms of Sandifer syndrome may include any combination of abnormal movements and/or positioning of head, neck, trunk and upper limbs, seizure-like episodes, ocular symptoms, irritability, developmental and growth delay and iron-deficiency anaemia. It is evident from the literature that many of the patients were originally misdiagnosed with various neuropsychiatric diagnoses that led to unnecessary testing and ineffective medications that may have caused significant side effects. Earlier diagnosis of Sandifer's would have allowed to avoid them.

As Sandifer syndrome is caused by gastro-oesophageal reflux, its investigations and management should be consistent with those of GERD. In terms of diagnostic procedures, 24-h oesophageal $\mathrm{pH}$ monitoring was positive in all the cases of Sandifer's where it was performed, while upper GI endoscopy \pm biopsy and barium swallow were diagnostic only in a subset of cases.

A range of treatment options were applied in the reviewed literature, including dietary changes (cow's milk exclusion, amino-acid-based formula), pharmacological management (alginates, proton pump inhibitors (PPIs)), enteral tube feeding, and surgical approach, when conservative management was ineffective (Nissen fundoplication is usually curative). The pharmacological treatment was often sufficient on its own to achieve the resolution of symptoms; however, further escalation of management was required in the cases of advanced disease. These treatment options are consistent with the 2015 NICE guideline on management of GERD in children and young people [22].

Successful treatment of the underlying gastro-oesophageal pathology led to a complete or near-complete resolution of the neurological symptoms in all of the reviewed cases.

\section{Discussion}

1. Sandifer syndrome may be difficult to recognise due to its nonspecific presentation; however, it is an important differential diagnosis to consider in children with neurological symptoms that remain unexplained by neurological investigations.

2. When Sandifer syndrome is suspected, 24 -h oesophageal $\mathrm{pH}$ monitoring is usually diagnostic; however, an empirical trial of pharmacological management (e.g., prescribing a PPI) is also appropriate without prior invasive investigation [31].

3. Once diagnosed, it can be successfully managed by treating the underlying GERD/hiatus hernia which typically leads to a complete resolution of all associated symptoms.

4. In the majority of patients, pharmacological management is sufficient for the resolution of symptoms. Other treatment options include dietary modifications, enteral tube feeding, and surgical management.

5. The choice of a management plan in each case depends on the severity and duration of the underlying condition, as well as individual responsiveness to treatment. 


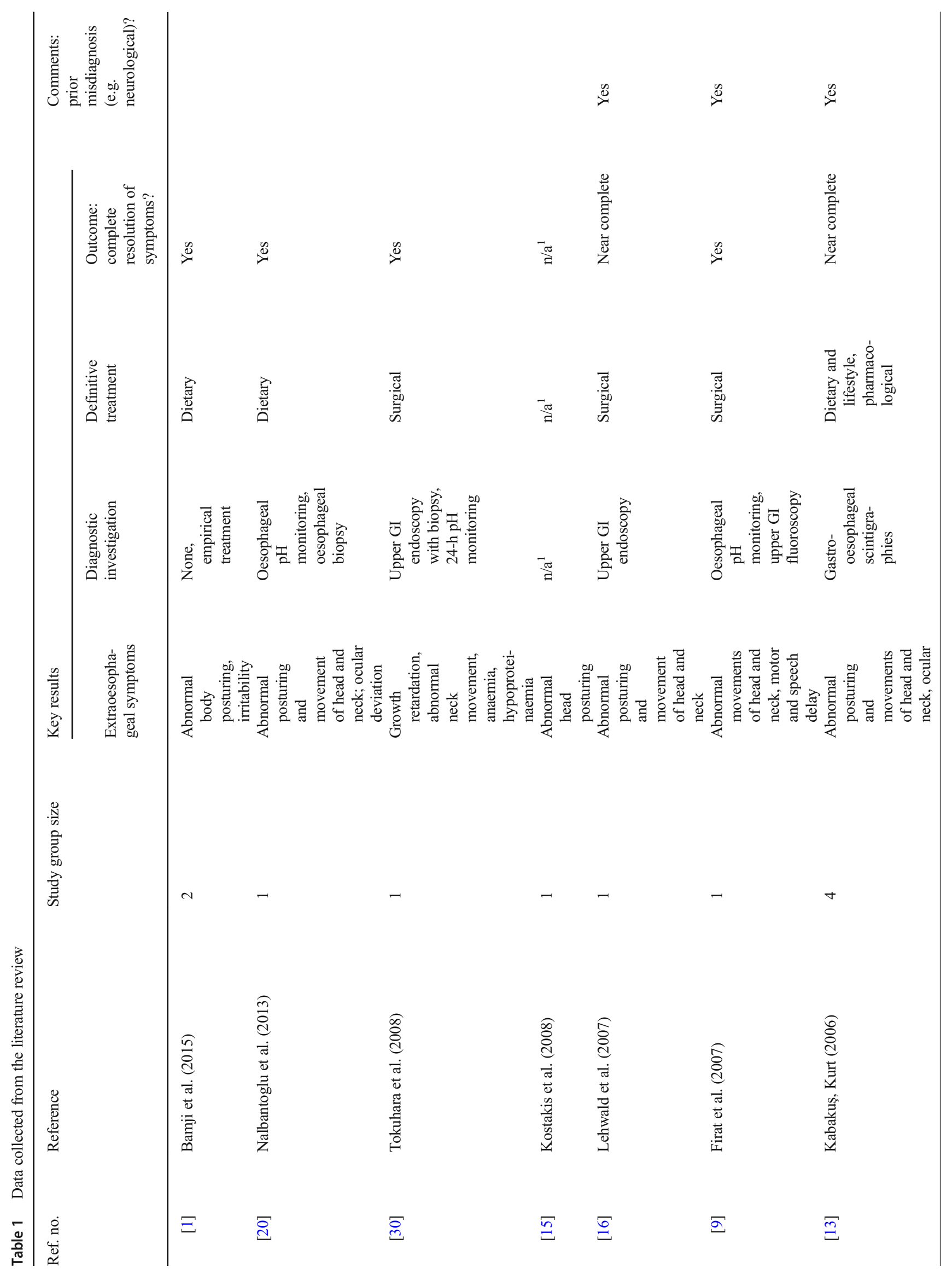




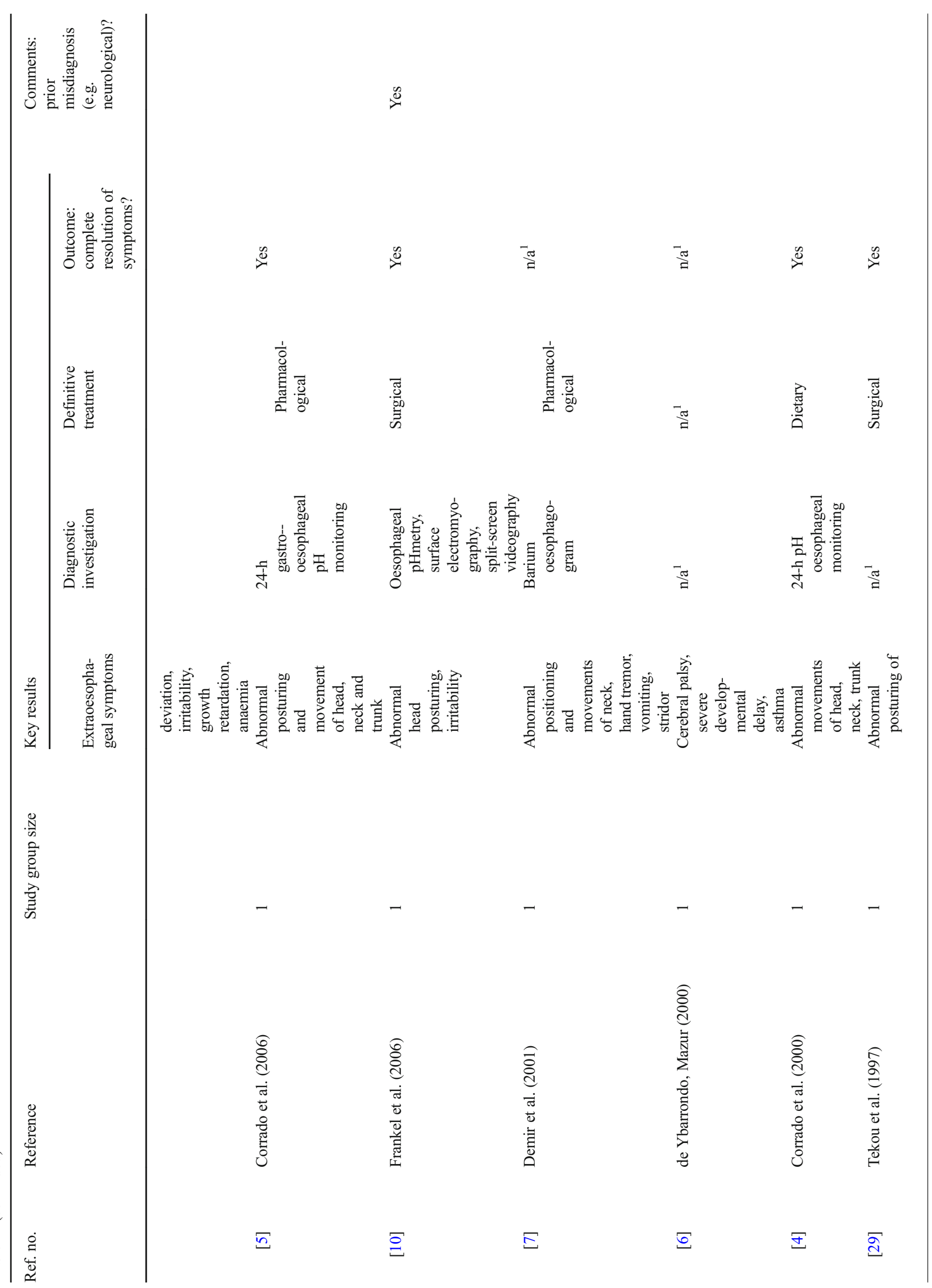




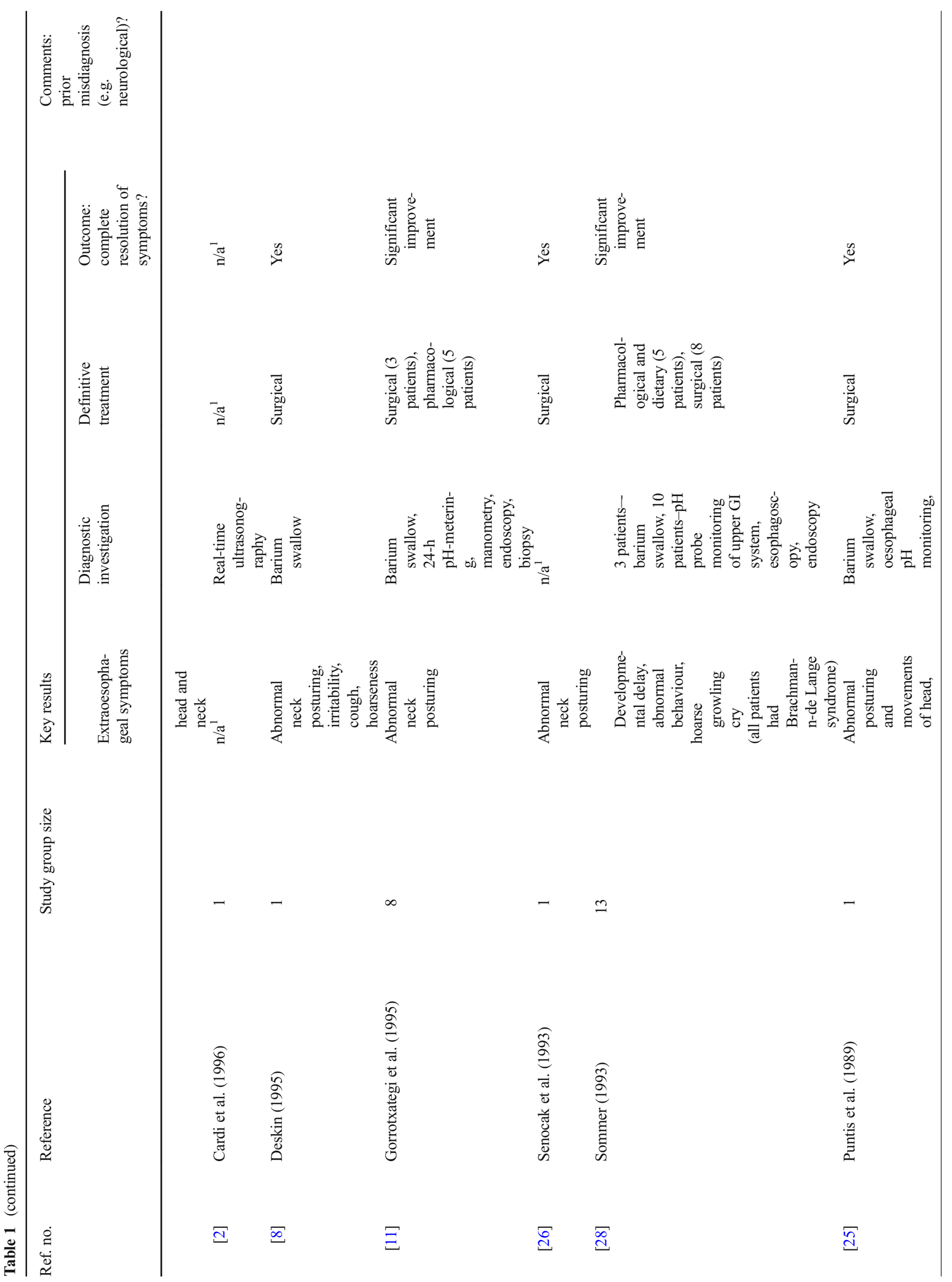




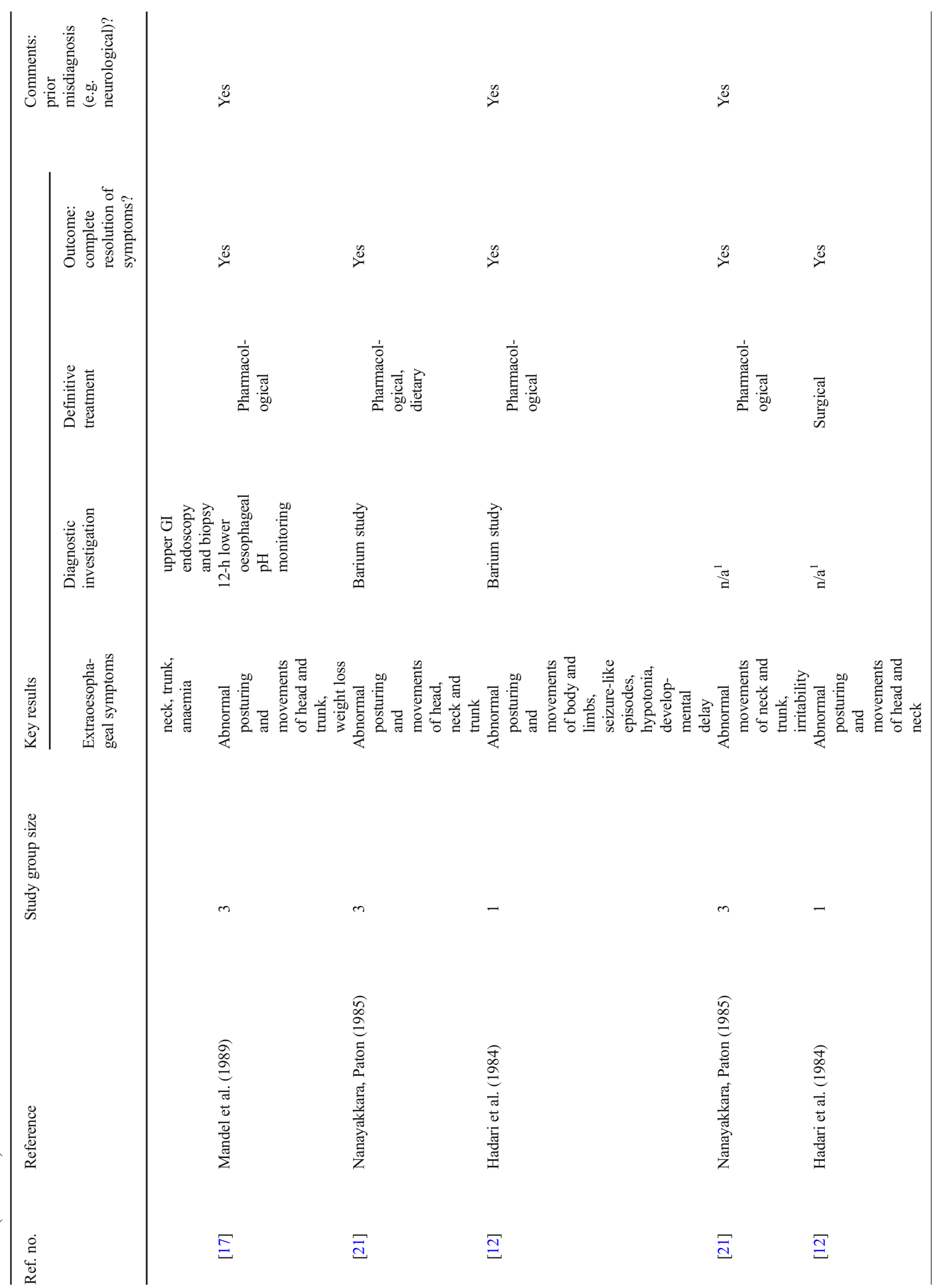




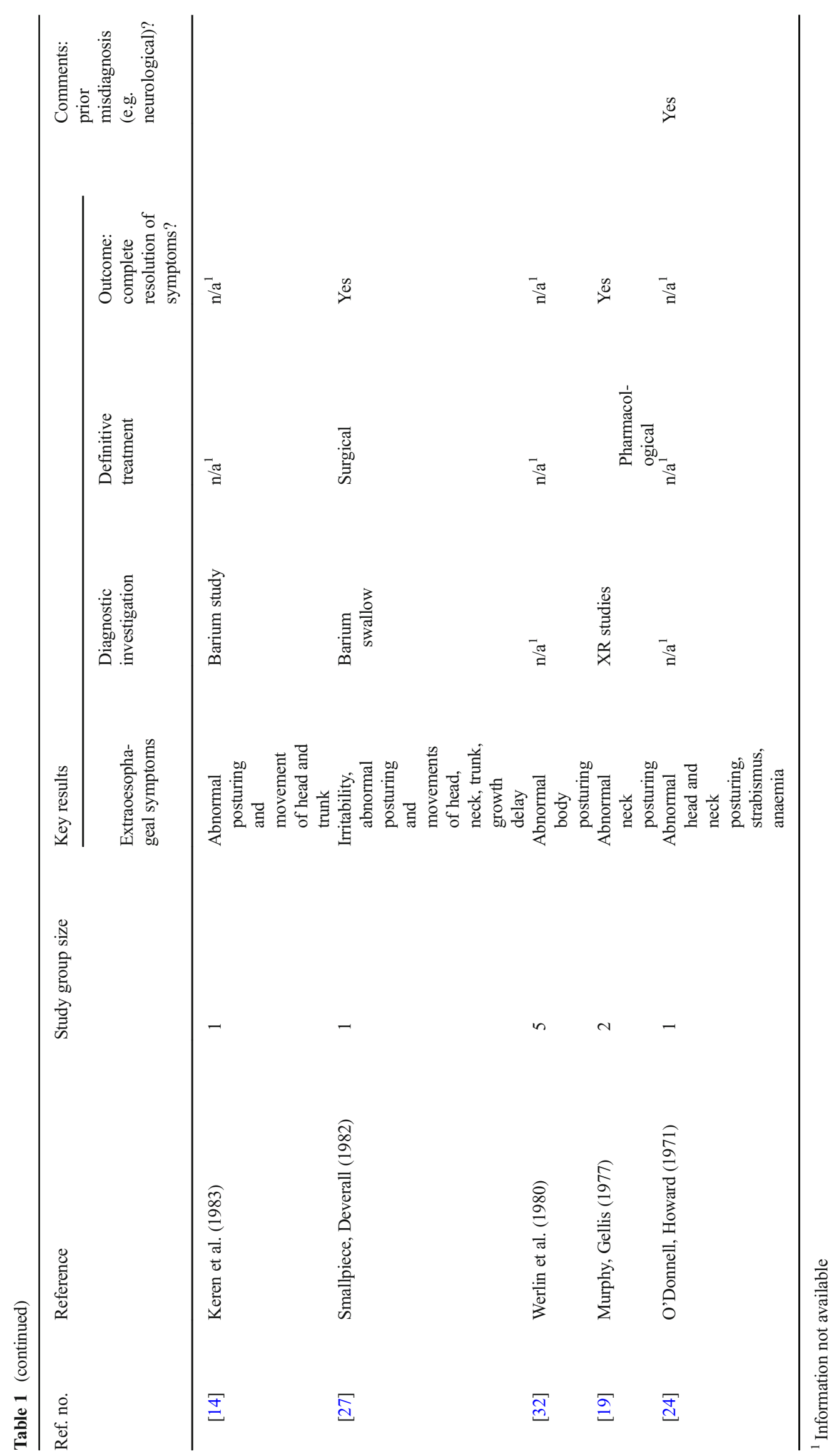




\section{Compliance with ethical standards}

Conflict of interest The authors declare that they have no conflict of interest.

Ethical approval This article does not contain any studies with human participants or animals performed by any of the authors.

Open Access This article is licensed under a Creative Commons Attribution 4.0 International License, which permits use, sharing, adaptation, distribution and reproduction in any medium or format, as long as you give appropriate credit to the original author(s) and the source, provide a link to the Creative Commons licence, and indicate if changes were made. The images or other third party material in this article are included in the article's Creative Commons licence, unless indicated otherwise in a credit line to the material. If material is not included in the article's Creative Commons licence and your intended use is not permitted by statutory regulation or exceeds the permitted use, you will need to obtain permission directly from the copyright holder. To view a copy of this licence, visit http://creativecommons.org/licenses/by/4.0/.

\section{References}

1. Bamji N, Berezin S, Bostwick H, Medow MS (2015) Treatment of Sandifer syndrome with an amino-acid-based formula. AJP Rep 5(1):e51-e52. https://doi.org/10.1055/s-0035-1545672

2. Cardi E, Corrado G, Cavaliere M, Capocaccia P, Matrunola M, Rea P, Pacchiarotti C (1996) Delayed gastric emptying in an infant with Sandifer syndrome. Ital J Gastroenterol 28(9):518-519

3. Cerimagic D, Ivkic G, Bilic E (2008) Neuroanatomical basis of Sandifer's syndrome: a new vagal reflex? Med Hypotheses 70(5): 957-961. https://doi.org/10.1016/j.mehy.2007.09.011

4. Corrado G, Cavaliere M, D'Eufemia P, Pelliccia A, Celli M, Porcelli M, Giardini O, Cardi E (2000) Sandifer's syndrome in a breast-fed infant. Am J Perinatol 17(3):147-150. https://doi.org/10.1055/s-2000-9285

5. Corrado G, Fossati C, Turchetti A, Pacchiarotti C, Nardelli F, D'Eufemia P (2006) Irritable oesophagus: a new cause of Sandifer's syndrome. Acta Paediatr 95(11):1509-1510. https:// doi.org/10.1080/08035250600643251

6. de Ybarrondo L, Mazur JL (2000) Sandifer's syndrome in a child with asthma and cerebral palsy. S Med J 93(10):1019-1021

7. Demir E, Saka E, Aysun S (2001) A case of Sandifer's syndrome with hand tremor. Turk J Pediatr 43(4):348-350

8. Deskin RW (1995) Sandifer syndrome: a cause of torticollis in infancy. Int J Pediatr Otorhinolaryngol 32(2):183-185

9. Firat AK, Karakas HM, Firat Y, Yakinci C (2007) Unusual symptom of intestinal malrotation: episodic cervical dystonia due to Sandifer syndrome. Pediatr Int 49(4):519-521. https://doi.org/10. 1111/j.1442-200X.2007.02409.x

10. Frankel EA, Shalaby TM, Orenstein SR (2006) Sandifer syndrome posturing: relation to abdominal wall contractions, gastroesophageal reflux, and fundoplication. Dig Dis Sci 51(4):635-640. https:// doi.org/10.1007/s10620-006-3184-1

11. Gorrotxategi P, Reguilon MJ, Arana J, Gaztañaga R, Elorza C, de la Iglesia E, Barriola M (1995) Gastroesophageal reflux in association with the Sandifer syndrome. Eur J Pediatr Surg 5(4):203-205. https://doi.org/10.1055/s-2008-1066205

12. Hadari A, Azizi E, Lernau O, Nissan S (1984) Sandifer's syndrome-a rare complication of hiatal hernia. A case report. Z Kinderchir 39(3): 202-203. https://doi.org/10.1055/s-2008-1044208

13. Kabakuș N, Kurt A (2006) Sandifer syndrome: a continuing problem of misdiagnosis. Pediatr Int 48(6):622-625. https://doi.org/10. 1111/j.1442-200X.2006.02280.x
14. Keren G, Frand M, Jonas A, Avigad I, Rotem Y (1983) Sandifer's syndrome following reverse gastric tube operation (Gavriliu's operation). J Pediatr Surg 18(5):632-633. https://doi.org/10.1016/ s0022-3468(83)80380-7

15. Kostakis A, Manjunatha NP, Kumar A, Moreland ES (2008) Abnormal head posture in a patient with normal ocular motility: Sandifer syndrome. J Pediatr Ophthalmol Strabismus 45(1):57-58

16. Lehwald N, Krausch M, Franke C, Assmann B, Adam R, Knoefel WT (2007) Sandifer syndrome-a multidisciplinary diagnostic and therapeutic challenge. Eur J Pediatr Surg 17(3):203-206. https:// doi.org/10.1055/s-2007-965145

17. Mandel H, Tirosh E, Berant M (1989) Sandifer syndrome reconsidered. Acta Paediatr Scand 78(5):797-799. https://doi.org/ 10.1111/j.1651-2227.1989.tb11150.x

18. Moore DM, Rizzolo D (2018) Sandifer syndrome. JAAPA 31(4): 18-22. https://doi.org/10.1097/01.JAA.0000531044.72598.26

19. Murphy WJ, Gellis SS (1977) Torticollis with hiatus hernia in infancy. Sandifer syndrome. Am J Dis Child 131(5):564-565. https:// doi.org/10.1001/archpedi.1977.02120180078015

20. Nalbantoglu B, Metin DM, Nalbantoglu A (2013) Sandifer's syndrome: a misdiagnosed and mysterious disorder. Iran J Pediatr 23(6):715-716

21. Nanayakkara CS, Paton JY (1985) Sandifer syndrome: an overlooked diagnosis? Dev Med Child Neurol 27(6):816-819. https://doi.org/10.1111/j.1469-8749.1985.tb03808.x

22. National Institute for Health and Care Excellence (2015) Gastrooesophageal reflux disease in children and young people: diagnosis and management [NG1]. https://www.nice.org.uk/guidance/ng1. Accessed 12 Oct 2018

23. Nuysink J, van Haastert IC, Takken T, Helders PJ (2008) Symptomatic asymmetry in the first six months of life: differential diagnosis. Eur J Pediatr 167:613-619. https://doi.org/10.1007/ s00431-008-0686-1

24. O'Donnell JJ, Howard RO (1971) Torticollis associated with hiatus hernia (Sandifer's syndrome). Am J Ophthalmol 71(5):1134-1137. https://doi.org/10.1016/0002-9394(71)90589-7

25. Puntis JW, Smith HL, Buick RG, Booth IW (1989) Effect of dystonic movements on oesophageal peristalsis in Sandifer's syndrome. Arch Dis Child 64(9):1311-1313. https://doi.org/10.1136/adc.64.9.1311

26. Senocak ME, Arda IS, Büyükpamukçu N (1993) Torticollis with hiatus hernia in children. Sandifer syndrome. Turk J Pediatr 35(3):209-213

27. Smallpiece CJ, Deverall PB (1982) Sandifer's syndrome: a new cause. Thorax 37(8):634-635. https://doi.org/10.1136/thx.37.8.634

28. Sommer A (1993) Occurrence of the Sandifer complex in the Brachmann-de Lange syndrome. Am J Med Genet 47(7):10261028. https://doi.org/10.1002/ajmg.1320470719

29. Tekou H, Akue B, Senah KC, Etey K, Dagnra PC (1997) Sandifer's syndrome-a report of one case. West Afr J Med 16(1):48-49

30. Tokuhara D, Yamano T, Okano Y (2008) A case of Sandifer's syndrome: significance in the differential diagnosis of growth retardation. J Paediatr Child Health 44(5):311-312. https://doi.org/10. 1111/j.1440-1754.2008.01304-01305.x

31. Vandenplas Y, Ashkenazi A, Belli D, Boige N, Bouquet J, Cadranel S, Cezard JP, Cucchiara S, Dupont C, Geboes K (1993) A proposition for the diagnosis and treatment of gastro-oesophageal reflux disease in children: a report from a working group on gastrooesophageal reflux disease. Eur J Pediatr 152:704-711. https:// doi.org/10.1007/BF01953980

32. Werlin SL, D'Souza BJ, Hogan WJ, Dodds WJ, Arndorfer RC (1980) Sandifer syndrome: an unappreciated clinical entity. Dev Med Child Neurol 22(3):374-378. https://doi.org/10.1111/j.14698749.1980.tb03719.x

Publisher's note Springer Nature remains neutral with regard to jurisdictional claims in published maps and institutional affiliations. 